\title{
ASSESSMENT OF THE CERVICAL COLLAR APPLICATION IMPACT ON THE CONDITIONS OF INTUBATION AND THE FEELINGS OF PATIENTS - PILOT STUDY
}

\author{
Michal Ladny ${ }^{1}$, Jacek Smereka², Lukasz Szarpak ${ }^{3}$, Jerzy Robert Ladny ${ }^{4}$ \\ 'Department of Trauma-Orthopaedic Surgery, Solec Hospital, Warsaw, Poland \\ ${ }^{2}$ Department of Emergency Medical Service, Wroclaw Medical University, Wroclaw, Poland \\ ${ }^{3}$ Department of Emergency Medicine, Medical University of Warsaw, Poland \\ ${ }^{4}$ Department of Emergency Medicine and Disaster, Medical University Bialystok, Poland
}

\begin{abstract}
INTRODUCTION: Securing the stability of the cervical spine is one of the basic procedures performed by medical personnel in trauma patients. Unfortunately, standard cervical collars limit the effectiveness of some procedures, including endotracheal intubation, as well as affect the pain sensations of the injured person. The aim of the study was to compare the influence of two different types of cervical collars on the technical conditions of endotracheal intubation and the patient's sense of comfort.
\end{abstract}

METHOD: The study was designed as a randomised, cross-over research and included 32 healthy paramedics, who had a cervical collar installed for 20 minutes in a randomised way. During the examination, the patient's comfort and pain resulting from the pressure on mastoid processes were evaluated.

RESULTS: Prior to the study, the mouth opening in the examined group was $51 \pm 12 \mathrm{~mm}$. After the set-up of the Patriot collar, the mouth opening amounted to $37 \pm 10 \mathrm{~mm}$, while in the NECKLITE collar group amounted to $49 \pm 13 \mathrm{~mm}(p<0.001)$. The use of a cervical collar reduced the degree of mouth opening by $27 \%$ when using a standard cervical collar, and less than $4 \%$ when using a NECKLITE collar. The pressure on the mastoid processes assessed on a 10-point scale varied between the cervical collars and amounted to $7 \pm 2$ points for Patriot and $1 \pm 1$ points for NECKLITE collar $(p<0.001)$. The pain sensations associated with the cervical collar were also varied and amounted to $6 \pm 3$ points for Patriot collar vs. $1 \pm 1$ points for NECKLITE collar $(p<0.001)$. Ninety-seven per cent of study participants declared, that they preferred the NECKLITE collar comparing to the Patriot cervical collar.

CONCLUSIONS: A standard cervical collar causes an increase in pain due to the pressure on the mastoid processes and a sense of discomfort for the patient. The NECKLITE collar thanks to the possibility of better fit to the patient's neck, does not cause any pain, and using this collar it is possible to perform endotracheal intubation without the need to unfasten it.

KEY WORDS: cervical collar, prehospital, emergency medicine, endotracheal intubation

Disaster Emerg Med J 2018; 3(1): 1-4 


\section{INTRODUCTION}

Stabilisation of the cervical spine in case of suspected spine injury is one of the basic procedures that should be performed by paramedics while securing a trauma patient $[1,2]$. One of the most common methods for securing the cervical spine is the cervical collar, which is intended to assist the rescuer with the maintenance of neutral alignment, prevention for lateral sway and anterior-posterior flexion and extension of the cervical spine during transport and routine patient care on movement [3-5]. In many cases, however, patients with head injuries experience altered consciousness and obstruction of the airway. Protection of airway patency in the case of cervical spine immobilisation using a standard cervical collar, as reported by Gawlowski et al. [6], may lead to a reduction in the effectiveness of endotracheal intubation.

The aim of the study was to assess the impact of cervical collar on the endotracheal intubation conditions and pain sensations associated with the stabilisation of the cervical spine with a cervical collar.

\section{METHOD}

The study was designed as a randomized cross-over research and the research protocol was accepted by the Institutional Review Board of the Polish Society of Disaster Medicine (Approval number: 153.01.2018. IRB). Thirty-two paramedics took part in the study.

Prior to the study, the maximum degree of mouth opening in the context of possible endotracheal intubation was assessed for all the participants, and the following measurement was performed while securing the neck with a cervical collar. During the study, the participants had a cervical collar in place for 20 minutes. Cervical neck stabilisation using a cervical collar was performed by an independent researcher with instructor certificates in the field of Prehospital Trauma Life Support. The study used two types of cervical collars (Fig. 1):

A) Ambu $^{\circledR}$ Perfit ACE ${ }^{\mathrm{TM}}$ (AMBU A/S, Ballerup, Denmark), which is a one-piece cervical rigid cervical spine immobilisation device;

B) NECKLITE emergency neck brace (FLAMOR SRL, San Pietro Mosezzo, Italy). This extraction collar is a one-piece moldable cervical spine immobilisation device.

During the study, the study participants were in a horizontal position on a transport stretcher. After the examination, the participants filled out

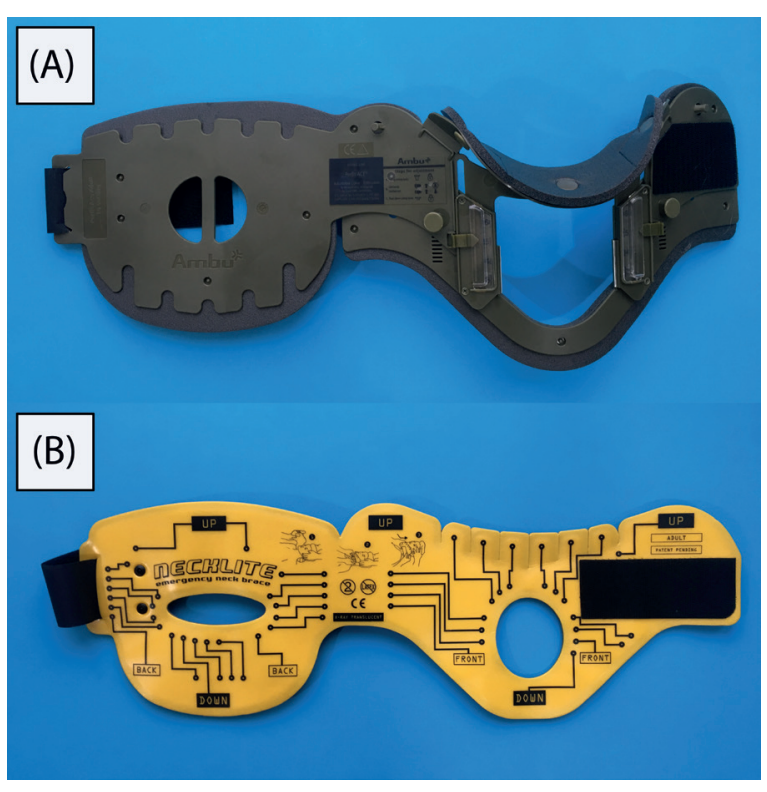

FIGURE 1. Cervical collars used in the trial: Ambu ${ }^{\circledR}$ Perfit ACE $^{\mathrm{TM}}$ (A); NECKLITE (B)

a questionnaire regarding the use of orthopaedic collars. The questionnaire included questions about the self-assessment of pain related to the cervical collar on a 10-point scale (1 - no pain, 10 - severe pain), and compression of the collar on the mastoid processes - also on a 10-point scale (1 - no pressure; 10 - strong pressure causing severe pain).

All statistical analyses were carried out using the Statistica 13EN program (StatSoft, Tulusa, OK, USA). Evaluation of the distributions of variables were performed using Levene's test for homogeneity of variances. A two-tailed value of $p<0.05$ was considered statistically significant.

\section{RESULTS}

Thirty-two paramedics participated in the study. During the control measurement, the degree of the mouth opening in the examined group was $51 \mathrm{~mm}$ [IQR; 46-54]. After the set-up of the AMBU collar, the mouth opening amounted to $37 \mathrm{~mm}$ [IQR; 29-42], while in the NECKLITE collar group amounted to $49 \mathrm{~mm}$ [IQR; 43-52]. This difference in the extent of mouth opening was statistically significant ( $p<0.001$; Fig. 2$)$. The use of a cervical collar reduced the degree of mouth opening by $27 \%$ when using a standard cervical collar, and less than $4 \%$ when using a NECKLITE collar.

The pressure on the mastoid processes assessed on a 10-point scale varied between the cervical col- 


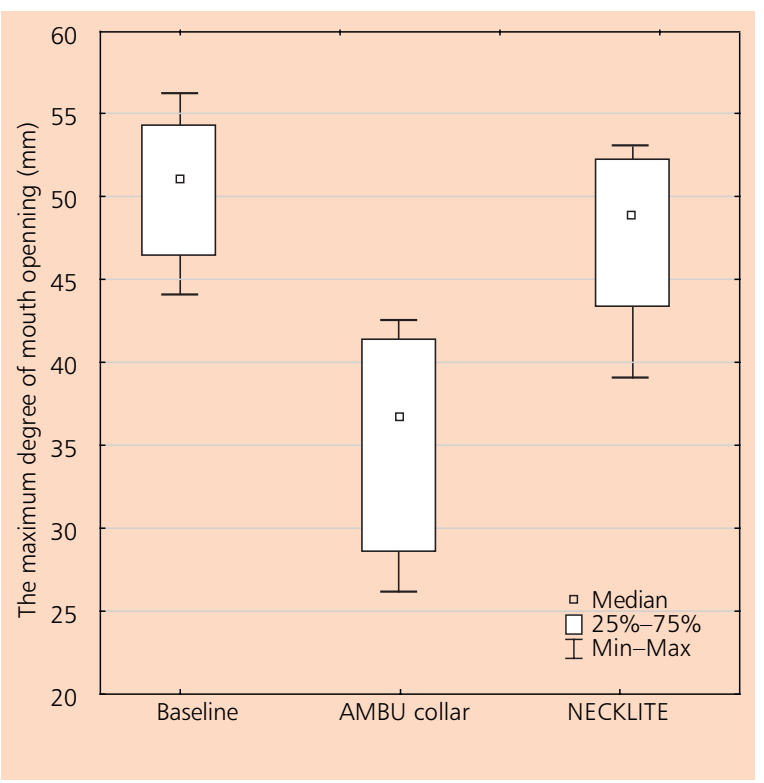

FIGURE 2. The maximum degree of mouth opening parameter

lars and amounted to $7 \pm 2$ points for AMBU and $1 \pm 1$ points for NECKLITE collar $(p<0.001$; Tab. 1$)$.

The pain sensations associated with the cervical collar were also varied and amounted to $6 \pm 3$ points for AMBU collar vs. $1 \pm 1$ points for NECKLITE collar $(p<0.001)$.

Ninety-seven per cent of study participants declared, that they preferred the NECKLITE collar comparing to the Patriot cervical collar.

\section{DISCUSSION}

The study was conducted to compare the influence of two different types of cervical collars on the technical conditions of endotracheal intubation and the patient's sense of comfort. To our knowledge, this was the first study in the world comparing different types of cervical collars in this aspect.

Currently, there is no consensus on how and whether to stabilise the cervical spine in pre-hospital care. The study by Benger et al. [7] indicated, that stabilisation of the cervical spine that was previously practiced was ineffective. Accordingly, it is currently aimed to use stabilisation methods more simple for medical personnel, as well as more comfortable for the patient. Bledsoe et al. [8] in the article "Why EMS should limit the use of rigid cervical collars", published in the Journal of Emergency Medical Services, as one of the reasons why we should reduce the use of cervical collar indicates the problem of airway management. In turn, Goutcher and Lochhead [9] indicated, that properly applied rigid cervical collar restricts mouth opening by $25 \%$ or more. If a standard cervical collar was used, similar results were obtained as in the Goutcher and Lochhead studies. However, if the NECKLITE cervical collar is used due to its construction, and it is possible to temporarily deflect the mandible supporting part without removing the entire collar, it is possible to fully open the mouth, which enables the possibility of more efficient endotracheal intubation. It is worth emphasising, that the degree of mouth opening is directly correlated with the effectiveness of endotracheal intubation performed using the direct laryngoscopy. However, as indicated by the number of studies conducted by Madziala et al. [10, 11] and Gawlowski et al. [6, 12], the efficacy of endotracheal intubation using a videolaryngoscope in the case of cervical spine stabilisation is as high as in normal airways.

Another aspect pointed out by Bledsoe et al. [8] is the occurrence of pressure on the mastoid processes, and thus the intensification of pain related to the cervical spine stabilisation using a cervical collar. In our study, the pressure inserted on mastoid processes and the associated discomfort were observed only in the case of using a standard cervical collar. It is due to the fact, that it is made of plastic, which in the case of a good fit causes pressure on numerous structures within the skull as well as the arms on which it rests. In the case of the NECKLITE collar, the feeling of pressure is negligible. It is dictated by the fact, that thanks to numerous incisions in the cervical collar, it can be appropriately adjusted to a specific patient, what reduces the feeling of discomfort associated with its use.

The third aspect discussed in the scientific literature [7], which advocates the non-use of cervical

Table 1. Parameters during cervical collar application

\begin{tabular}{|l|c|c|c|}
\hline & AMBU cervical collar & NECKLITE & $p$ value \\
\hline Maximum degree of mouth opening $[\mathrm{mm}]$ & $37[\mathrm{IQR} ; 29-42]$ & 49 [IQR; 43-52] & $\mathrm{p}<0.001$ \\
\hline Pressure on mastoid processes [1-10] & $7 \pm 2$ & $1 \pm 1$ & $\mathrm{p}<0.001$ \\
\hline Pain complaints [1-10] & $6 \pm 3$ & $1 \pm 1$ & $\mathrm{p}<0.001$ \\
\hline Patient preferences & $3 \%$ & $97 \%$ & $p<0.001$ \\
\hline
\end{tabular}


collars, is the increase of intracranial pressure after cervical collars use. Cervical collars are often tight against the neck. Impaired blood return from brain can therefore result in increased intracranial pressure. Currently, studies on the impact of NECKLITE cervical collar on the increase in intracranial pressure are in progress, however, given that patients have no discomfort or pain associated with the pressure caused by the NECKLITE collar, it is likely that this collar will not affect intracranial pressure as it was for example in the case of standard cervical collars.

This study has numerous limitations. One of the main is the fact, that it was carried out on healthy volunteers, not on trauma patients requiring cervical spine stabilisation. However, the selection of such a study group was dictated by the fact that only under such conditions it was possible to conduct the trial in a cross-over and randomized manner, without any potential risk to the patient's health. Another limitation of the study was the use of only two collars, however, one of the most common types of cervical collars and the most modern neck collar NECKLITE were used. NECKLITE collar, among the available on the market, is most optimal to adapt to the patient's anatomy.

\section{CONCLUSIONS}

In our study, the use of a standard cervical collar was associated with significant limitation of mouth opening, which may result in a reduction of chances of effective endotracheal intubation. It was also associated with significant pressure on mastoid processes and with pain. The use of the NECKLITE collar allowed the full fit of the collar to the anatomical conditions of the patient and was associated with greater comfort of stabilisation compared to a standard cervical collar.

Conflict of interest: Lukasz Szarpak is working as a scientific consultant for PerSys Medical.

\section{REFERENCES}

1. Rahmani F, Pouraghaei M, Moharamzadeh $P$, et al. Effect of Neck Collar Fixation on Ventilation in Multiple Trauma Patients. Trauma
Mon. 2016; 21(4): e21866, doi: 10.5812/traumamon.21866, indexed in Pubmed: 28180117.

2. Peck GE, Shipway DJ, Tsang K, et al. Cervical spine immobilisation in the elderly: a literature review. Br J Neurosurg. 2018 [Epub ahead of print]: 1-5, doi: 10.1080/02688697.2018.1445828, indexed in Pubmed: 29488398.

3. Barati K, Arazpour M, Vameghi R, et al. The Effect of Soft and Rigid Cervical Collars on Head and Neck Immobilization in Healthy Subjects. Asian Spine J. 2017; 11(3): 390-395, doi: 10.4184/asj.2017.11.3.390, indexed in Pubmed: 28670406.

4. Kreinest M, Goller S, Rauch G, et al. [Parameters influencing the preclinical application of cervical collars]. Unfallchirurg. 2017; 120(8): 675-682, doi: 10.1007/s00113-016-0207-z, indexed in Pubmed: 27357352.

5. Pryce R, McDonald N. Prehospital Spinal Immobilization: Effect of Effort on Kinematics of Voluntary Head-neck Motion Assessed using Accelerometry. Prehosp Disaster Med. 2016; 31(1): 36-42, doi: 10.1017/ S1049023X1500552X, indexed in Pubmed: 26674843.

6. Gawlowski P, Smereka J, Madziala M, et al. Comparison of the Macintosh laryngoscope and blind intubation via the iGEL for Intubation With C-spine immobilization: A Randomized, crossover, manikin trial. Am J Emerg Med. 2017; 35(3): 484-487, doi: 10.1016/j. ajem.2016.11.064, indexed in Pubmed: 28041757.

7. Benger J, Blackham J. Why do we put cervical collars on conscious trauma patients? Scand J Trauma Resusc Emerg Med. 2009; 17: 44, doi: 10.1186/1757-7241-17-44, indexed in Pubmed: 19765308.

8. Bledsoe B, Carrison D. Why EMS Should Limit the Use of Rigid Cervical Collars. Journal of Emergency Medical Services. 2015; Jan 26.

9. Goutcher $\mathrm{CM}$, Lochhead V. Reduction in mouth opening with semi-rigid cervical collars. Br J Anaesth. 2005; 95(3): 344-348, doi: 10.1093/ bja/aei190, indexed in Pubmed: 16006487.

10. Madziala M, Smereka J, Dabrowski M, et al. A comparison of McGrath MAC $®$ and standard direct laryngoscopy in simulated immobilized cervical spine pediatric intubation: a manikin study. Eur J Pediatr. 2017; 176(6): 779-786, doi: 10.1007/s00431-017-2909-9, indexed in Pubmed: 28429117.

11. Madziala M. Endotracheal intubation during manual inline cervical stabilization performed by nurses. Am J Emerg Med. 2016; 34(12): 2456-2457, doi: 10.1016/j.ajem.2016.09.030, indexed in Pubmed: 27692934.

12. Gawlowski P, Smereka J, Madziala M, et al. Comparison of the ETView Single Lumen and Macintosh laryngoscopes for endotracheal intubation in an airway manikin with immobilized cervical spine by novice paramedics: A randomized crossover manikin trial. Medicine (Baltimore). 2017; 96(16): e5873, doi: 10.1097/MD.0000000000005873, indexed in Pubmed: 28422820. 